ritic eruptions they had nothing to object; but the
volcanic facies appeared to then a privilege restricted to recent geological times. To this the present writer of Damas" only when he was fortunate enough to ram ble over North Wales, and gather with his own hands pieces of vesicular lava enibedded in the tuffs of the
Snowdon, or bowlders of true felsite, lying at the base of the Cambrian series at Llanberis.
Not only has Sir Archibald, in common with hi is to herve as a comforting example for those who refuse countrymen, always escaped that kind of misconcep- to acknowledge any other means of genuine success
tion, but he will have contributed more effectively than constant labor and faithfulness to duty. than any other to place the matter in the true light Thanks to the cliffs of Scotland, he has been able to trace the roots of old volcanoes, to show true volcanic
bombs entombed in sediments, and to mark the site bombs entombed in sediments, and to mark the site his previous paper on Teen heaped up. Likewise, in lished by indisputable sketches that the granitic rocks of the islands of Mull and Skye were ejected during belong to the central mass of intrusions, the lateral veins of which have taken the form of granophyres.
There is another kind of useful geological work which There is another kind of useful geological work which
Sir Archibald has a right to be credited with : we allude to the restoration of the most friendly relations of London. For many years those relations had been maintained at a rather low temperature; both independent geologists and government surveyors showed, icism than to brotherly co-operation. This period of misunderstanding is now well over. Thanks to the present director, the Geological Society has more than
once received the early flower of the capital results of Sir Archibald has solemnly sanctioned the return of Sir Archibald has solemnly sanctioned the return
advancement of geological science in England.

This is a very brief and imperfect account of the
chief work accomplished by the field geologist, a work chief work accomplished by the field geologist, a work
which would have been sufficient for the whole of a
man's life. But we have now to consider in Sir Archiman's life. But we have now to consider in Sir Archi-
bald the master who has been engaged in important to the chair of geology at Edinburgh he had the whole work of that department to organize, a task which may be wearisome, but which involves great benefit for a man of labor, as he must face every difficulty, that is required for teaching. To that we are indebted for the undisputed superiority which Sir Archibald has displayed in his "Text-book," as well as in his a very model of clearness, whereby it has been once writing elementary books who are in the fullest forsession of the whole miatter. Likewise he is the author of small books or "primers" on physical geology and
geography, of which some hundreds of thousands of copies have been sold, and which have been translated
into most European languages, as well as into some Asiatic tongues. This exceptional success will be easily
understood if we remember that in Sir Archibald's works the traditional barrenness of geology is always for nature. Nobody has done more than he to associate geological science with the appreciation of scenery. In numberless writings he has undertaken to Awong others, reference may be made to the volume with its Physical Geology," first published in 1869, of which a new edition "appeared in 1887 ; also to "GeoGeographical Society for 1879 ; and "On the Origin of the Scenery of the British Isles," published in Nature
(vol xxix., pp. 347, 396, 419, 442). (vol xxix.,pp. $347,396,419,442)$.
Nevertheless, whatever might have been the attain-
ments of the geologist and of the teacher, they would not have been sufficient to secure universal recogniiwith the best powers as a writer. From the beginning he was strongly convinced of the importance of cultivating the literary element in scientific exposition, not pirle to those outside the circle of actual workers, as Abroad," but because he did not admit the right of a
man of science to appear before the public without man of science to appear before the public without
putting on the "nuptial dress." Every one who knows Sir Archibald will readily admit that in doing so he is not impelled by a desire for personal display. He "Res non verba" might well serve him as a motto, and whoever has seen his silent but piercing attention in listening to some scientific controversy would never be
tempted to suspect him of a wish to search after resounding manifestations. But he has too much of the artist's temper to neglect correctness and elegance in
the utterance of his thoughts. And since nothing in the world is less common than the union of scientific insight and acuteness with a vivid appreciation of that Sir Archibald's fame has passed far beyond the circle of professional men. The portrait will be duly completed when it is added that no onn could have a
better renown for frankness, fair deitling and perfect better renown for frankness, fair deitia

trustworthiness in every relation of life.
It is highly gratifying for England that the recognition of such achievements has not been left to future times, and that the present generation has not and fruitful labor. He was admitted to the Royal Society before reaching the age of thirty, a most unusual honor; he has been vice-president, and was re1890 an associate of the Berlin Academy : elected by the Royal Society of Sciences at Gottingen, after the death of Studer, the Nestor of Swiss geologists ; enNaturalists of Moscow, etc., he was chosen in 1891 as a correspondent by the French Academy of Sciences, orary LL.D. of the Universities of St. Andrews and Edinburgh, he has received the Murchison medal of
the Geological Society of London, and twice the Mac-
Dougal Brisbane gold medal of the Royal Society of
Edinburgh has been conferred on him, in recognition of the zeal aud skill displayed in explaining the geothe summit of his career, and not so heavily laden with years but that we may express for him the wish
ad multos annos. Let us hope that he will long remultos annos. Let us hope that he will long re-
main at the head of the distinguished staff to which

HEAT AND CHEMICAL ENERGY. By A. Naumann.

THE TRANSFORMATION OF HEAT INTO PERMANENT CHEMICAL ENER Y IN THE PRODUCTION
OF WATER PRODUCER AS AND CARBONIC ACID PRODUCER A AS.

THREE methods are chiefly available for the transormation of coal into heating gas : the production of lluminating gas by destructive distillation of coal, ments of water on heated fuel, and that of producer In the production of illuminating gas only a small
In

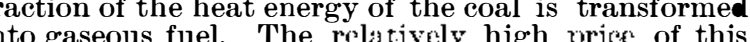
nto gaseous fuel. The rolatively high price of this
gas prevents its application on a lirge seatre as a heatng gas; on a small scale it is employed for heating purposes and motive power in the absence of a cheaper Trge towns.

he formation of water gas is endothermic; heat is $\mathrm{H}_{2} \mathrm{O}$ (liquid) $+\mathrm{C}=\mathrm{H}_{2}+\mathrm{C} \mathrm{O} \ldots-38,770$ calories.

The somewhat complicated apparatus required for the production of water gas only allows of its prepar the advantage is so considerable that in the towns of North Anerica water gas has been substituted, to a
reat extent and sometimes altogether, for illuminatg gas for lighting purposes, its lighting power being obtained by so-called carbureting. $\dagger$ is comparatively
The production of producer gas is
imple and easily carried out. The formation of proimple and easily carried out. The formatic

$\mathrm{C}+0+53 \cdot 6$ parts by weight of nitrogen $=$ air

$\mathrm{C} \mathrm{O}+5 \% 6$ purt.s by weight of nitrogen $+29,690$ calories producer gas

The amount of heat here indicated causes the theoretical temperature of producer gas at the moment of specific heats of its constituents are the same at high 29,690 calories) thus indicated is utilized if the gas be ost if the gas is conveyed to any distance or stored nd allowed to cool to the ordinary temperature of the air, $15^{\circ}$ Cent., the amount of heat there available being only that evolved by the combustion of the carbonic
oxide in the gas that is, 67,960 calories. Out of a total
of 97.650 calories available, only 67,960 calories would be utilized in the latter case, corresponding to a waste vailable.

Two methods are within our reach for converting nto permanent chemical energy the quantity of heat ducer and incorporating it in the gas.
Either so much water may be introduced into the producer with the air as to absorb from the heat gentact with the fuel, thereby producing hydrogen and
carbonic oxide, which mix with the ordinary producer gas generated at the same time, enriching it and formng a heating gas, which may be called water producer gas : or carbonic acid may be similarly intro-
duced into the gas producer to form carbonic oxide, which mixes with the ordinary producer gas, genermay be called carbonic acid producer gas.
In the following tables for each of these two heating In the following tables for each of these two heating
cases the composition, heat of combustion, rise of tem perature of the flame, and heat given up by the prodacts of combustion for a reduction of $1^{\circ}$ in temperature are compared with the corresponding amounts for
producer gas. I may here mention that the method of procedure for determining these values is tedious and
troublesome, and I therefore limit myself to tabulating The rults.

The composition of water producer gas from fluid water at 15 and gaseous water at $15^{\circ}$ is calculated
rom the following thermochemical equations II. and III., and that of carbonic acid producer gas from

I. $\mathrm{C}+\mathrm{O}+53 \cdot 6$ parts by weight of nitrogen $=$

C $\mathrm{O}+53 \cdot 6$ parts by weight of nitrogen $+29,690$ calorie

II. $\quad \mathrm{H}_{2} \mathrm{O}$ (liquid) $+\mathrm{C}=-\mathrm{H}_{2}+\mathrm{C} \mathrm{O}-38.770$

III. $\quad \mathrm{H}_{2} \mathrm{O}$ (gaseous at $\left.15 \mathrm{O}\right) \cdot\left(\mathrm{C}=\mathrm{H}_{2}+\mathrm{CO}-27,970\right.$

IV. $\quad \mathrm{C} \mathrm{O}_{2}+\mathrm{C}=2 \mathrm{C} \mathrm{O}-38.270$

In the following tables are given separately, first volumes of the gases formed and mixed in the producer and of the water gas which together form water
producer gas ; and, secondly, the volumes of the chem* "Berichte der Deutschen Chemischen Gesellschaft," No. 25, 1892

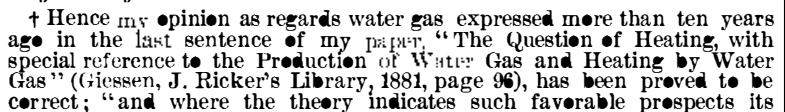

ical constituents of those gases ; for carbonic acid proucer gas the volumes of the producer gas and the cid introduced into the producer are first given, and those gases.

I.-Composition of producer gas from pure carbon : Carbonic oxide....... 34.3 per cent. by volume.
Nitrogen......... 65.7 $100 \cdot 0$

II.-Composition of water producer gas :
1. Producer ga miquid $\mathrm{H}^{2} \mathrm{O}$ From gaseous $\mathrm{H}^{2} \mathrm{O}$
at $155^{\circ}$.
Percentage by volume. $15^{\circ}$. $42 \cdot 1$
$100 \cdot 00 \quad 100 \cdot 0$

Equivalent to :

2. $\left\{\begin{array}{lrr}\text { Hydrogen ...... } & 17 \cdot 2 & 21 \cdot 1 \\ \text { Carbonic oxide.. } & 39 \cdot \cdot 7 & 40 \cdot 9 \\ \text { Nitrogen ........ } & 43 \cdot 1 & 38 \cdot 0 \\ & 1000 & 100 \cdot 0\end{array}\right.$

III.-Composition of carbonic acid producer gas : Percentage.

1. $\left\{\begin{array}{l}\text { Producer gas } \ldots \ldots \ldots \ldots \ldots \ldots \ldots \\ \text { Carbonic oxide made from carbonic } \\ \text { acid and carbon................ }\end{array}\right.$

Equivalent to :

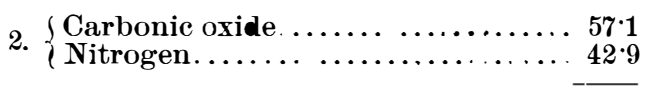

$100 \cdot 0$

A glance at the above volume percentage composuperiority of water producer gas and of carbonic acid
producer as over ordinary producer gas. This superiority is shown still more clearly by a comparison of the following values : 1 . The heat of combustion of a liter of each gas calculated from the above composition and the known heat of combustion of their constitulated from the temperature of combustion and specifio heat and quantity of gases existing after combustion. a liter of gas by reducing the temperature $1^{\circ}$.

For comparison these values are also calculated and given for water gas, it being assumed that combustion
in all cases is effected with only the quantity of air theoretically necessary.

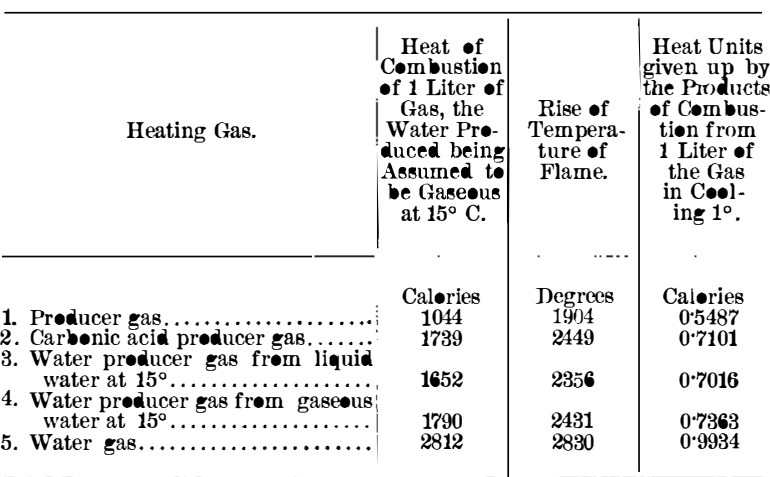

The above changes of sensible heat into permanent experimentally determined, have also been applied in The so-called Dowson gas* is technically water producer gas, where for its production air and steam are introduced together into the hot fuel. The values for fhe steam only vary slightly from those given above heat of evaporation of water at $15^{\circ}$ and at higher temperatures is but slight. Such water producer gas had, according to Dowson's town data, the following cont-
position, I. ; another, according to a paper of Schil-

\begin{tabular}{|c|c|c|}
\hline Constituents. & \multicolumn{2}{|c|}{$\begin{array}{l}\text { I. } \\
\text { In volumes per cent }\end{array}$} \\
\hline Hydrogen, ..... & & 17 \\
\hline Carbonic oxide & 25.07 & 23 \\
\hline Methane...... & 0.31 & \\
\hline Ethylene ..... & 0.31 & \\
\hline Carbonic acid & 0.57 & \\
\hline Nitrogen ... & $48 \cdot 98$ & 52 \\
\hline Oxygen.. & & \\
\hline
\end{tabular}

$100 \cdot 00 \quad 100 \cdot 0$

The discrepancies in the composition of theoretical by the as and of that used in practice are explained acid, which if completely reduced would give double assumed to be used in the formation of theoretical water producer gas in the above calculations. In Dowson's arrangement the excess heat of production of the producer gas is actually transformed into the chemical energy of water gas, produced by the producer, and their decomposition by the coal, which,

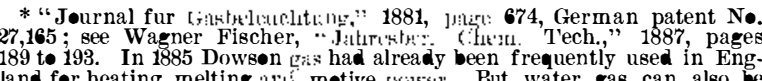

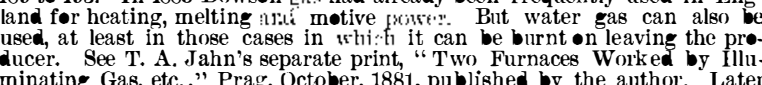

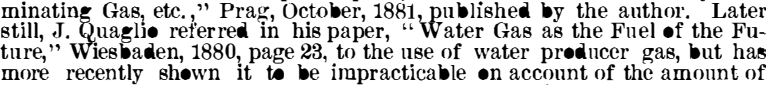

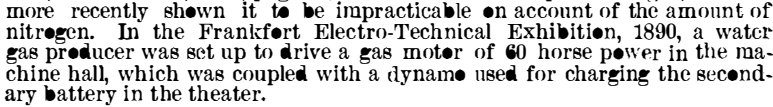

† Wagner Fischer, "Annual Chem. Tech.," 1887. page 171. $\ddagger$ R. Biedermann, "Cheru. Tech. Annual," 1889-90, pages 12 and 206. 
being added to the producergas, forms water producer for a month at this temperature. Samples kept at from taneously used, and the glycerin will be mixed in the

gas. -perandi is partially carried out; steam is also blown products of combustion is led into the producer at high temperature. As these products of combustion and also carbonic acid producer gas are formed. The by the conversion of steam into water gas $\left(\mathrm{H}_{2} \mathrm{O}+\mathrm{C}\right.$ $\left.=\mathrm{H}_{2}+\mathrm{CO}\right)$, and the $\mathrm{CO}_{2}$ into
the result being an increase of the hydrogen and car-
bonic oxide in the gas made. To produce water gas bonic oxide in the gas made. To produce water gas
from steam and hot carbon without any extraneous heat, the steam would have to be introduced at the
temperature of $3,230^{\circ}$. To produce carbonic oxide temperature of $3,230^{\circ}$. To produce carbonic oxide
from carbonic acid and heated carbon without any
extraneous heat, the carbonic acid would have to be introduced at a temperature of $4,008^{\circ}$. However, the nitrogen contained in the hot products of combustion available for the above-named processes of conversion. But the introduction of relatively large volumes of
nitrogen contained in the products of combustion into nitrogen contained in the products of combustion into
the gas producer, and thus going into the heating gas
produced, prevents the total utilization of the prodnew form Siemens furnace not more than half the products of combustion are returned to the gas pro-
ducer. The theoretical limit of this amount depends upon the temperature of the returned products of com-
bustion, also on their composition, as per table below, assuming that only the theoretical amount of air required for perfect combustion is used and taken with for one liter of producer gas, water producer gas, car-
bonic acid producer gas, and, for comparison, Weights of products of combustion in grammes in one liter of theoretical heating gas :

\begin{tabular}{|c|c|c|c|}
\hline \multirow{2}{*}{ Heating Gas. } & \multicolumn{3}{|c|}{$\begin{array}{l}\text { Products of Combustion } \\
\text { in Grammes. }\end{array}$} \\
\hline & $\mathrm{CO}_{2}$. & $\mathrm{N}$. & $\mathrm{H}_{2} \mathrm{O}$. \\
\hline 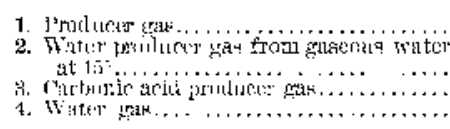 & $\begin{array}{l}0 \cdot 6762 \\
0 \cdot 806 \\
1 \cdot 125 \\
1 \cdot 064\end{array}$ & $\begin{array}{l}1 \cdot 6474 \\
1 \cdot 965 \\
1 \cdot 909 \\
3 \cdot 207\end{array}$ & $\begin{array}{l}0 \cdot 171 \\
0 \cdot 504\end{array}$ \\
\hline
\end{tabular}

According to scientific observation these are the
highest results which can be attained theoretically for highest results which can be attained theoretically for producer gas and carbonic acid producer gas. A compractice would be a guide as to how far the heat in so avoid errors in treating fuel.

\section{BACILLI IN BUTTER.}

By Grace C. Frankland.

THE fact that milk affords a particularly suitable
medium for the growth and multiplication of most medium for the growth and multiplication of most as a dangerous vehicle for the proprapution of disease. use. and so destroying any pathogenic microbes which may be present, is almost universal, and recently a
number of special pieces of apparatus have been devised
for household use, insuring the efficient so-called "pasteurization" of milk. In England, however, we theria and typhoid fever having been not inf requently
traced to a particular milk supply. In a paper by
Cnopf on the bacterial contents of milk it is stated that on one occasion out of every thirteen samples of milk supplied to Paris one was found to contain tubercle bacilli, while it is well known that the germs of readily in this medium. But although milk has been gation, comparatively little is known of the microbial bacilli purposely rubbed into butter could be demon-
strated after thirty-two days, while typhoid bacilli similarly introduced were found af ter three weeks, and Gasperini discovered the latter in butter even after 120 "Bacteriologische Studien uber Butter," in the Archiv fur Hygiene, in which he has recorded his investigations on the micro-organisms found in Munich butterand thus furnish an interesting supplement to what is already known concerning the longevity of pathogenic already known concerning the longevity of pathogenic prepared from fresh cream and were investigated as
soon as josible after the butter was made. It was
found that the number of microbes differed accordin found that the number of microbes differed according as the portion for experiment was taken from the out
side or from the interior of the piece of butter. Thu pat contained $2,465,555$, on the outside in the same quantity as many as $47,250,000$ micro-organisms were tions, it was estimated that the interior of a lump of
butter possessed from 10 to 20 millions of bacteria in a single grm. Lafar is inclined to regard this as an under rather than an over statement of the number, tain proportion of microbes which will not develop at the ordinary temperature, or on the gelatine-peptone
medium usually employed. He graphically puts it
that in some cases it is conceivable that the number of organisms swallowed with a moderately sized slice population of Europe! Jufir found that butter kept in a refrigerator with a tenperature of between $0^{\circ}$ to diminution took place, although the sample was kep * English patent No. 4,644, of 1889 . $12^{\circ}$ to $15^{\circ} \mathrm{C}$. exhibited a marked increase in the number tand-I examined ten samples of glycerin coming fron of micro-organisms, a rise from 6 to 35 millions being ten different works. As I wished to detect smallest
observed in the course of 9 days, while when placed traces, I used silver nitrate instead of mercuric bichlorin the incubator $\left(35^{\circ}\right.$ C.) after 4 days the bacteria had ide. Three of the samples would have to be rejected,
fallen from 25 to 10 millions, and after 34 days only 5 four samples contained very small traces, which might per cent. of the original number present were discov- be disregarded, while three only were absolutely free erable. Experiments were also made to ascertain what ' from arsen ic.
was the bacterial effect of adding salt to butter kept in 'There is still another process for saponifying fats, bers were thereby considerably reduced, yet, even a very large scale indeed-that which yields the soap when as much as 10 per cent. of salt was added, the lye glycerin. At last year's conference the glycerin
complete destruction of the bacteria was not accom-

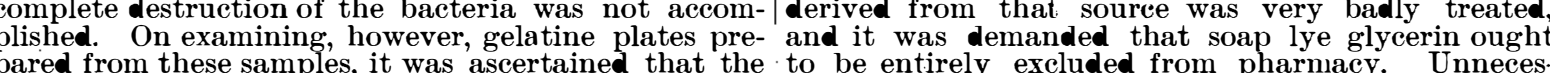
consted almost entirely of a pure sary precaution!-up to now, at least - for no chem cultivation of one particular microbe, which was ap- ically pure glycerin has been prepared hitherto from had grown and multiplied to the exclusion of nearly all the other bacteria originally present. When samples the result was rather different, for while there was
noreapparentconnection between the proportion salt added and the diminution in the number of bac
teria, more varieties of micro-organisms were found on the gelatine plates. But in this case, also, the germiter were also examined, and were invariably found to be much poorerin bacteria than ordinary butter. Thus
while the smallest number found in one grm. wa microbes was the minimum. Two varieties of bacill have been isolated and described, which were found very constantly present in butter throughout these
investigations. They are beautifully illustrated and colonies at the end of the paper. Lafar purposes continuing his investigations, and it is to be hoped the examination of butter for pathogenic micro-organ-
isms, about which so little is known, will form an important feature in
undertake-Nature.

\section{GLYCERIN.*}

By J. Lewkowitsch, Ph.D.

AT the outset,I wish to disclaim any intention on my part of bringing anything new before you. But havI might perhaps supplement the remarks made last year by Mr. Siebold and several other gentlemen in the
discussion following Mr. Siebold's paper.
This will be done mostly from the manufacturer's This will be done mostly from the manufacturer's
point of view, as manufacturing processes cannot be upposed to be generally known, and it is not at all unlikely that erroneous opinions may be current among
those not conversant with practical processes used in chemical works.

During the last year it has been repeatedly stated
that some samples of glycerindestined for pharmaceut ical purposes contained arsenic, a fact which was not vious reasons they did not care to enlighten the consumers. The arsenic in the glycerin owes its existence the manufacturing process. It has been pointed out
by several gentlemen in last year's discussion, that
glycerin purified by distillation would not be contaminted by this poisonous substance; although it is but fair to say that Mr. Allen had some doubts about it,
still, in the concluding remarks it was distinctly stated
that arsenic could be removed by distillation. This is not so, as the simple fact will show that now
all glycerin for pharmaceutical purposes is distilled, nay, even double distilled, glycerin. The times when
glycerin was being prepared by other processes of refinglycerin was being prepared by other processes of refin
ing have gone by, and a glycerin which had not been pharmaceutical purposes. But to remove every doubt I prepared the substance
formed when arsenious acid is dissolved in glvcerin, a substance which has been described by Schiff, and
later on by Jackson, who apparently overlooked the later on by Jackson, who apparently overlooked the
earlier publication of Schiff. This substance is the
arsenious ether of glycerin. $\mathrm{AsO}_{3}\left(\mathrm{C}_{3} \mathrm{H}_{5}\right)$. On being arsenious ether of glycerin, $\mathrm{AsO}_{3}\left(\mathrm{C}_{3} \mathrm{H}_{5}\right)$. On being
heated to $250^{\circ} \mathrm{C}$., it decomposes, while arseniureted
hydrogen and other volatile arsenious compounds distill over. At the same temperature glycerin distills also
over, and it is quite evident, therefore, that any arsenic
contained in glycerin will distill along with it. The experiments which I carried out couli not show any Arer result.

Arsenic contained in glycerin cannot be removed by distillation, and to my knowledge there is no process Pure glycerin, free from arsenic, can therefore be ob-
practical scale. tained from such sources only where reagents not contaminated with arsenic are being used. As it has been
suggested last year that glycerin emanating from cer-
tain processes ourl tit to be rigorously excluded by the Pharmacopoeia, I may be allowed here to very briefly review from our point of view the processes used for manufacturing glycerin. The raw materials are excluhydrolysis the glycerin as a by-product.
Glycerin free from arsenic will be obtained in those processes where the fats are hydrolyzed by means of
water, whether it be used in the liquid state, under high pressure, or as superheated steam. The lime
saponification, which is yet largely practiced, especially in smaller works, will, as a rule, also yield an arsenic-
free glycerin. On the contrary, all glycerin ceming from works where the sulphuric acid saponification is tract all the arsenic from the sulphuric acidl. There is however. no doubt that even such glycerin would be
pure, as far as arsenic is concerned, if sulphuric acid free from arsenic were used, as it may be prepared from
the sulphur obtained by Chance's process. There is consequently no doubt that there are
sources from which one may easily obtain a pure sources from which one may easily obtain a pure
glycerin. With a view to ascertain whether there are arsenic-for in many works several processes are simul* British Pharnaceutical Conference, Leeds. soaplees, owing to the difficulties incident to the puri
fication of it.
Being wishful to prove here that soap lye glycerin has a far worse reputation than it--or, or let me say weeks to prepare chemically pure glycerin from soap lees, not in the laboratory, but on a large scale in the
works. I had to use such glycerin as I just had at hand, and as this contained, owing to the impure reagents, some arsenic, I had on starting to expect a glycerin pointed out above, only of secondary importance, as with purer reagents, and the real difficulties are lying n quite another direction.
Arsenic, although the most objectionable impurity is, however, not the only one which may be found in
"chemically pure" glycerin. As the British Pharmacopeia treats glycerin somewhat cursorily, I nay be perhaps be found useful The glycerin may contain organic impurities, either
fatty acids, etc., or so-called polyglycerols, under having a higher boiling point than glycerin itself. The way to test for the latter is to gently evaporate a known quantity of glycerin in a platinum dish at a tempera-
ture of $160^{\circ} \mathrm{C}$. The residue left, from which the ash will give a fair indication as to the care with which the glycerin has been distilled. The following table gives the residues for eight
chemically pure" glycerins, arranged according to
the quantity of organic residue, to which I have added the quantity of organic residue, to wh
the analysis of the soap lye glycerin :

\begin{tabular}{|c|c|c|}
\hline & $\begin{array}{l}\text { Organic residue. } \\
\text { Per cent. }\end{array}$ & $\begin{array}{l}\text { Ash. } \\
\text { Per cent. }\end{array}$ \\
\hline & .. 0.0243 & 0.00603 \\
\hline & 0.0327 & 0.0050 \\
\hline & 0.0328 & 0.0140 \\
\hline$(b) \ldots \ldots \ldots \ldots \ldots \ldots$ & 0.0267 & 0.0102 \\
\hline 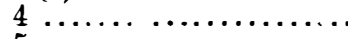 & 0.0360 & $0 \cdot 0138$ \\
\hline & 0.0371 & 0.0081 \\
\hline & 0.0443 & 0.0066 \\
\hline & 0.0738 & 0.014 \\
\hline & 0.0751 & 0.0154 \\
\hline & 0.0931 & 0.0305 \\
\hline
\end{tabular}

No. 3 represents the figures found for two batches of he soap lye glycerin, which I have shown. Fatty acids, as butyric acid, etc., and other organic
impurities will be easily detected by testing with which is recommended by the Gernan Pharmacopoeia. It is required of a good glycerin that it should not reduce the silver within fifteen minutes. This test is ject any glycerin which reduces silver nitrate in less ammoniacal silver nitrate is a little too rigorous, as at an elevated temperature ; in fact, of all the glycerin would have to be rejected. Testing with nitrate of

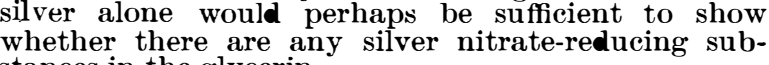
Under No. 68 of the blue list an answer is reguested
and factory answer to that question, as we are not sat in possession of sufficient quantitative material. Lately,
two methods have been proposed for the estimation of glycerol, which seem specially suitable in a gremt many
cases, unhappily not in all. The first met horl, based cases, unhappily not in all. The first methen hased aluminis night be thus estimated. The second method acetate-requires highly concentrated solutions, and
would, of course, be completely useless when other substances are present which combine with acetic anhydride, as would be the case with, $e$, g., glycerinum acidi acired to have a method for completely transforming
the glycerol into a weighable substance, e. g., a tribro-

PHYSICAL PHENOMENA AT LOW TEMPERATURES.

PICTET has experimented on the chemical and physical pherinuena observable at very low temperapressors and aspirators, a mixture of sulphur dioxide and carbon dioxide will give a temperature of $-110^{\circ}$. a minimum temperature of $-210^{\circ}$ to $-213^{\circ}$. These low thermometer, or by alcohol or ether thermoneters, verified by the $h$ ydrogen thermometer. The author thesevery low temperatures pass readily through almost
all bodies. Thus a vessel at $-110^{\circ}$ for exanple will cool of cotton enveloping it be $50^{\mathrm{cm}}$ or $10^{\mathrm{cm}}$ or only $2^{\mathrm{cm}}$ in thickness. Moreover, he finds that when chloroform is
immersed in nitrogen monoxide at $-120^{\circ}$, a therject any glycerin which reduces silver nitrate in less
than twenty four hours. I think that the test with to the question how to estimate glycerol in phlisrulause where no other organic substance is present which
might yield oxalic acid. The glycerol in glycerinum acidi tannici. For such preparations it would be reall bodies. Thus a vessel at $-110^{\circ}$ for example will cool
with practically the same rapidity whether the laver 